https://doi.org/10.52505/lecturi.2021.05.06

\title{
VECINĂTĂȚILE SINTACTICE ALE VERBELOR DE ACT,IUNE (CU SENS DE CREARE, MODIFICARE, DISTRUGERE ŞI DEPLASARE A OBIECTULUI)
}

\author{
Elena CONSTANTINOVICI \\ Institutul de Filologie Română „Bogdan Petriceicu-Hasdeu”, Chișinău
}

\begin{abstract}
Rezumat. Articolul tratează aspectul sintagmatic al verbelor de acțiune fizicăa. In funcție de subclasă și de sensurile pe care le are, verbele din această clasă implică 2 actanți de bază - agentul și pacientul - cu rolurile respective. Pe lângă aceasta, printre vecinătățile sintactice ale acestor verbe figurează destinatarul și instrumentul (existent în structura de adâncime), precum și alte circumstanțe, de cele mai multe ori, facultative.
\end{abstract}

Cuvinte-cheie: verb, sintagmatic, actant, circumstanțe, schemă semanticosintactică, acțiune, agent, pacient, instrument.

Abstract. The article deals with the syntagmatic aspect of physical action verbs. Depending on the subclass and the meanings they express, the verbs in this class involve 2 basic actants - the agent and the patient - with the respective roles. In addition, among the syntactic neighborhoods of these verbs appears the recipient and the instrument (existing in depth structure), as well as other circumstances, often optional.

Keywords: verb, syntagmatic, actant, circumstances, semantic-syntactic scheme, action, agent, patient, instrument.

Verbele de acțiune în general se asociază cu o impresionantă diversitate semantică. Asta pentru că este clasa de verbe cu o frecvență mare în limbă și cu cea mai mare varietate de procese pe care le exprimă, iar majoritatea sunt procese dinamice. Clasa verbelor de acţiune este cea mai numeroasă. Unităţile lexicale cuprinse de această clasă sunt eterogene atât sub aspect semantic, cât şi gramatical. Există mai multe grupuri lexico-semantice în cadrul clasei verbelor de acțiune: verbele care semnifică acțiuni fizice (a ara, a face, a scrie, a tăia), acțiuni intelectuale (a cugeta, a gândi, a raționa), verbele de declarație (a vorbi, a spune, a zice), verbele de mișcare (a alerga, a merge, a călători) etc. Verbele de acțiune 
se caracterizează printr-o mare varietate de scheme semantico-sintactice și printr-o diversă combinație de actanţi și roluri asociate.

Pentru a dezvălui parțial această diversitate, în cele ce urmează, vom centra descrierea pe prezentarea vecinătătilor sintactice ale unor verbe de acțiune fizică, reprezentative pentru limitele modelului sintagmatic specific, în constelaţia sensurilor pe care le exprimă şi a actanţilor pe care îi comandă. Pentru a descifra mecanismul de constituire a tiparelor sintagmatice ale verbelor în cauză, pentru a descoperi locurile libere deschise de ele, precum și actanții pe care îi guvernează și pentru a proba validitatea cercetării, sensurile vor fi ilustrate cu exemple exceptate din corpusul constituit pentru subproiectul Structurile sintactice de bază ale limbii române.

Exprimând acțiuni concrete ale participanților la situație (om, mecanism, fenomen al naturii), lexemele verbale din această subclasă au sensul generic ,a face, a realiza ceva". Semantica verbelor care exprimă acţiuni fizice este foarte largă. În literatura de specialitate se vorbește despre 4 subclase:

1) Crearea obiectului: a confecționa, a crea, a fabrica, a face, a produce, a realiza etc.

2) Modificarea obiectului: a modifica, a schimba, a preface, a reface, a transforma etc.

3) Distrugerea, sustragerea obiectului: a distruge, a confisca, a fura, a sustrage etc.

4) Deplasarea obiectului: a deplasa, a muta, a permuta, a strămuta, a transfera etc.

Verbele de acțiune, în general, și verbele de acțiune fizică, în special, au constituit obiectul de studiu al mai multor lucrări. (A se vedea: PanăDindelegan, 1974; Evseev, 1974; Vulpe, 2002, p. 38-90; Bărbuță, 1996, p. 57-65; GALR, 2005, p. 326-330, Constantinovici, 2001, p. 160-166; 2007, p. 55-64) etc.

Rolul decisiv în diferenţierea semantică a verbelor îi revine ansamblului de actanţi implicaţi de aceste verbe. $\mathrm{Cu}$ alte cuvinte, determinanţilor care exprimă subiectul, obiectul, destinatarul și instrumentul. Printre exponentele clasei verbelor de acțiune fizică ce semnifică crearea obiectului se numără verbele: a clădi, a construi, a confecționa, a coase, a crea, a croşeta, a dura, a edifica, a executa, a fabrica, a face, a impleti, a meşteri, a modela, a prepara, a produce, a realiza, a tricota, a zidi etc. Verbul director al clasei este a face. Este un verb polisemantic, preponderent tranzitiv, cu schema semanticosintactică de bază $\mathrm{N}_{1}+\mathrm{V}+\mathrm{N}_{2}$, care se descifrează prin < cineva face ceva $>$, dar are și ocurențe intranzitive și pronominale, unde schemele diferă. (Notă. Schemele sintactice de bază asemănătoare pentru diverse verbe se vor ilustra o 
singură dată. Cele care conțin actanți suplimentari se vor da la locul potrivit.) Din bogata paletă de sensuri, puține încadrează verbul dat în grupul verbelor creării. E vorba de sensurile:

1. A crea.

$\checkmark$ A face ceva: o rochie, un costum, un dulap, o casă, o jucărie, o ladă, un gard, mobilă, pantofi, un om de zăpadă, flori din hârtie, o gaură în perete.

- Ion îşi face casă. Nu eu am făcut fotografile alea. Uzina face o sută de automobile intr-o zi.

2. A găti, a prepara.

$\mathrm{N}_{1}+\mathrm{V}+\mathrm{N}_{2}+\mathrm{N}_{3}$ (D),

$\diamond$ A face ceva cuiva: mâncare, salată, pâine, o prăjitură, cafea, ceai din plante medicinale.

- Maria face mâncare copiilor. Le-am făcut oaspeților câte o cafea.

3. A compune, a scrie, a realiza, a alcătui, a întocmi.

$\checkmark$ A face ceva: o traducere, poezii, o lege, o convenţie, un tablou.

- Am făcut o listă cu toate cărțile pe care vreau să le citesc. Ion face proză. Noi vom face o lucrare despre proteine. In acest caz va trebui să facem un plan alternativ. Elevul și-a făcut temele.

4. A câştiga, a agonisi.

$\diamond$ A face ceva: bani, milioane, avere.

- Cred că vom face afaceri împreună.

Celelalte sensuri ale verbului a face (fără a lua în considerare și varianta lui pronominală) exprimă fie modificarea obiectului până la distrugerea lui: a preface, a schimba; a se îmbolnăvi, a face ceva una cu pământul (Ei fac din noapte zi., Băutura te face din om neom., Din coadă de câine, nu poți face sită de mătase., Ion face pe nebunul și nu vine la cursuri., Ion a făcut gripă., Expertul a făcut praf lucrarea mea., Explozia a făcut casa noastră una cu pământul.); fie calificarea lui: a numi, a cataloga, a practica, a studia (L-a făcut prost I măgar / mincinos pe colegul său., Lumea l-a făcut hoț., Aceste roluri l-au făcut celebru pe actor., El face matematica la universitate.); fie deplasarea obiectului: a străbate, a parcurge (Mașina a făcut 60 de mii de kilometri. Făceam zilnic câte $10 \mathrm{~km}$. Au făcut $20 \mathrm{de} \mathrm{km}$ pe jos, prin frig.) și altele. Verbul a face a constituit obiectul mai multor studii, două dintre care nu pot fi trecute cu vederea. E vorba de un articol semnat de Oana Magdalena Cenac (2007, p. 318-322) unde se discută fenomenul sinonimiei sintactice ,între construcțiile cu a face și un substantiv, adjectiv sau altă parte de vorbire, pe de o parte, și, pe de altă parte, cu verbele înrudite derivațional cu substantivul sau adjectivul respectiv" (p. 319). Un alt studiu cuprinzător referitor la disponibilităţile sintactice ale verbului $a$ (se) face este realizat de Elena Zgârcibaba (2015, p. 8-11). 
Verbul a crea, verb tranzitiv, se încadrează în totalitate în grupul verbelor creării, ca verb bivalent:

1. A produce, a realiza ceva nou, ceva ce nu a existat.

$\diamond$ A crea ceva: un dispozitiv, o maşină, un nou model, o siglă nouă pentru un produs.

- Michelangelo a creat o sculptură care îl reprezintă pe Moise. Cercetătorii au creat un robot care poate fi dirijat cu ajutorul gândurilor.

2. A înfiinţa, a funda, a întemeia.

$\diamond$ A crea ceva: o instituţie, o şcoală, un stat naţional, unitar, un curent filozofic, o teorie.

- Aceste ţări au creat un fond de dezvoltare regională. Comisia va crea cadrul legislativ pentru activitatea comercială.

3. A alcătui, a compune, a elabora.

$\diamond$ A crea ceva: un nou cuvânt, un roman, o piesă de teatru, o operă de artă.

- Dramaturgul a creat multe piese de teatru. Cred că am creat un raport echilibrat.

4. A pregăti, a forma (pentru o misiune, o carieră etc.).

$\diamond$ A crea pe cineva / ceva: specialişti, cadre, ingineri, rezerve, noi locuri de muncă, condiţii de dezvoltare, condiţii pentru succesul (unei acţiuni, unei întreprinderi).

- Au promis că vor crea noi locuri de muncă. Şefii le-au creat toate condiţiile pentru muncă. Există întreprinderi care creează specialiști.

\section{A cauza, a determina.}

$\diamond$ A crea ceva: o impresie, o bună dispoziţie, emoţii pozitive, o stare de spirit, o stare de indispoziţie, o stare de plictis, iluzii false, o tensiune nervoasă, motive de enervare, necazuri, dificultăţi, probleme, complicaţii, dependență, agitație, tulburare, confuzie, haos, panică în rândul oamenilor / printre oameni, dezordine, o situaţie dificilă, o situaţie explozivă, dezbinare în rândurile (unui partid, unei organizaţii), o diversiune, un precedent, o situaţie mai bună, un nume, o clientelă // din nimic.

- Şuvoaiele de apă le-au creat dificultăţi turiştilor. Aceste măsuri creează incredere în procesul de instruire. Vom crea un precedent care ar putea fi utilizat şi in alte domenii.

După cum se poate observa din cele de mai sus, pentru verbele creării, actanții de bază sunt agentul și obiectul (cu rol de rezultat). Ceilalți actanți, printre care destinatarul, sunt facultativi.

Din subgrupul verbelor care exprimă modificarea obiectului, foarte numeros, de altfel, fac parte: a corecta, a desăvârşi, a întregi, a înnoi, a îndrepta, a imbunătăți, a modifica, a moderniza, a normaliza, a perfecţiona, a preface, 
a prelucra, a preschimba, a raţionaliza, a reconstrui, a rectifica, a redresa, a reforma, a reface, a renova, a repara, a schimba, a transforma, a sistematiza etc. Schema semantico-sintactică de bază este $\mathrm{N}_{1}+\mathrm{V}+\mathrm{N}_{2}$.

Verbele a modifica și a transforma țin de subgrupul de verbe ale acțiunii fizice din subclasa modificării obiectului.

A schimba.

$\diamond$ A modifica ceva: o pălărie, o haină, un text, un proiect, un program, o lege, constituţia, ordinea, regulile după bunul plac, proprietăţile unui metal, construcţia unei maşini.

- Administratorii rețelei au modificat parolele. Parlamentul a modificat radical propunerile comisiei. Inginerii au modificat varianta inițială a proiectului.

A transforma v. tr.

A modifica aspectul, forma, caracterul etc.

$\mathrm{N}_{1}+\mathrm{V}+\mathrm{N}_{2}+\hat{\imath} n \mathrm{~N}_{3}$.

$\diamond$ A transforma ceval pe cineva: apa în vin, apa în gheaţă, plumbul în aur, o substanţă în alta, un ogor în păşune, un teren în parc, curentul alternativ în curent continuu, vorba în faptă, o încercare într-un fapt, îndoiala în certitudine, necesitatea în virtute, înfrângerea în victorie / radical, complet.

- Războiul a transformat oraşul înfloritor într-un morman de ruine. Primăria a transformat clădirea în muzeu. Folosind acest program poți transforma orice fotografie într-o splendidă pictură. Vor transforma acest spital într-o fortăreață. Să nu transformăm acest frumos eveniment într-o competiție. Şi-a transformat complet casa. El vrea să transforme lumea.

Complementul prepozițional este o ocurență obligatorie pentru verbul a transforma.

Din subgrupul de verbe cu sensul de distrugere, de nimicire a obiectului fac parte: a asasina, a distruge, a doborî, a desfiinţa, a devasta, a extermina, a executa, a extirpa a înjunghia, a împuşca, a lichida, a masacra, a mistui, a nărui, a omorî, a pârjoli, a prăpădi, a potopi, a pulveriza, a rade, a răpune, a sfâş̧ia, a sugruma, a strangula, a suprima, a tăia, a tortura, a ucide. Pentru acest grup, verbele se clasifică în funcție de valoarea semantică animat/inanimat a actantului=subiect și a actantului=obiect direct. De exemplu, verbul $a$ executa se încadrează în clasa verbelor creării dacă nominalul care exprimă subiectul este animat (+uman), iar cel care exprimă obiectul direct este inanimat: Fiica mea a executat o broderie fină. Când însă nominalele care exprimă subiectul și obiectul direct sunt ambele animate (+ uman), verbul dat ține de subgrupul verbelor de distrugere: Pirații au executat un ostatic.

$A$ distruge este un verb tranzitiv care se încadrează plenar în acest subgrup. După cum se poate observa din sintagmele și enunțurile cu/pe care 
le construiește, pe lângă actanții obligatorii, verbul dat necesită și diverse circumstanțe pentru a exprima situația descrisă. În cazul acestui verb, nu mai contează semul animat/inanimat.

1. A nimici.

$\checkmark$ A distruge ceval pe cineva: o clădire, un pod, un drum, un oraş, o instalaţie, o proprietate, o persoană, un adversar, o armată, orice urmă, dovezile, o teorie, un argument// cu mâinile goale, puțin câte puțin, fărâmă cu fărâmă, complet, din temelii, prin foc, printr-o explozie, prin acte de vandalism.

- O bombă a distrus casa. Printr-un foc de artilerie inamicul a distrus gara. Uraganul a distrus construcțiile. Dezastrele naturale pot distruge populaţia umană. Acidul distruge ţesuturile. Rugina distruge fierul. Focul a distrus totul. Dacă vrei sa distrugi o tară, atunci ucide-i sistemul de învățământ.

2. A ruina.

$\diamond$ A distruge ceva: sănătatea, organismul, viața, fericirea, speranţele, iluziile, reputaţia, poziţia socială, familia, căsnicia cuiva.

- Băutura i-a distrus organismul. Un rău ascuns îl distruge. Ai distrus viața unui om azi. Lucrul acesta imi distruge familia. Mi-ar putea distruge cariera. Nu îmi vei distruge restul vieții. Nu pot distruge căsnicia copiilor mei.

Verbele care semnifică deplasarea obiectului fac parte din grupul mai general al verbelor de mișcare: a aduce, a arunca, a căra, a coborî, a duce, a deplasa, a evacua, a importa, a împrăştia, a mişca, a muta, a remorca, a ridica, a rostogoli, a transfera, a trage, a urca.

Vecinătăţile sintactice ale verbelor din acest subgrup sunt mai diversificate. De exemplu, verbul a arunca, în ocurențele sale tranzitive, se construiește cu un obiect direct, cu un complement indirect, cu un complement prepozițional și $\mathrm{cu}$ circumstanţiale, preponderent, de loc:

1. A azvârli.

$\mathrm{N}_{1}+\mathrm{V}+\mathrm{N}_{2} / /+$ Circ. .

$\diamond$ A arunca ceva: o piatră, mingea, suliţa, discul, o greutate, o bilă, servieta, un geamantan, hârtiile, hainele, pantofii, undiţa, bombe // pe fereastră, peste gard, din tren, peste bord, pe jos, pe bancă, pe raft, în apă, în mare, pe mal, în aer, afară, într-un colţ, în toate părţile, cu forță, cu violență, claie peste grămadă.

- E momentul să aruncați mingea. Băiatul a aruncat o piatră în apă. Vizitiul a aruncat cocoşul în fântână. Valurile au aruncat luntrea pe mal. Impactul a aruncat autoturismul pe contrasens. Vulcanul aruncă lavă.

$\mathrm{N}_{1}+\mathrm{V}+\mathrm{N}_{2}+\mathrm{N}_{3}$ (D) .

$\diamond$ A arunca ceva cuiva: mingea, cheile, banii// în faţă.

- Stăpânul i-a aruncat câinelui un os. Marinarii i-au aruncat celui prins în vârtej de ape un colac de salvare. 


\section{A lepăda.}

$\diamond$ A arunca ceva: gunoiul, un palton vechi, hainele uzate, lucrurile nefolositoare, mâncarea expirată// la gunoi, la coş, la fier vechi, în stradă.

- Ion a aruncat hainele vechi. Poţi să arunci aceste boarfe. Locuitorii acestor apartamente aruncă gunoiul pe fereastră direct în stradă. Fă două copii și aruncă originalul.

Ca verb intranzitiv, cu sensul $<$ a da cu ceva în cineva $>$ are următoarea schemă sintactică:

$$
\mathrm{N}_{1}+\mathrm{V}+c u \mathrm{~N}_{2}+\hat{\imath} n \mathrm{~N}_{3} \text {. }
$$

$\diamond \mathrm{A}$ arunca cu ceva în cineva / după ceva: cu bulgări de zăpadă, cu o piatră.

- Copiii aruncau cu bulgări de zăpadă în ferestre. A fost reţinut de poliţie pentru că aruncă cu pietre după mașini. Oamenii aruncă cu pietre numai în pomii cu roade.

Caracteristic pentru verbele de acțiune, în special pentru cele de acțiune fizică, este actantul cu rol de instrument din structura lor de adâncime. De exemplu, verbele: a croșeta, a pieptăna, a secera, a săpa, a vâsli etc. conţin în structura lor de adâncime semele $<$ a acţiona + instrumentul indicat de tema verbală $>$. La aceste verbe actantul cu rol de instrument are, de obicei, întrebuințare absolută. Dintre enunțurile: Maria croșetează un mileu. Și Maria croșetează un mileu cu croșeta. sau Eu o pieptăn pe fica mea. și Eu o pieptăn pe fica mea cu pieptenele., o întrebuințare mai frecventă o au primele, dat fiind principiul economiei în limbă sau al efortului minim. Actantul cu rol de instrument nu se actualizează, el rămânând în structura de adâncime.

Acesta este tabloul sumar al vecinătăților sintactice ale verbelor de acțiune fizică. După cum e lesne de observat, verbele date se construiesc, obligator sau facultativ, cu actanți și cu circumstanțe, în funcție de subgrupul pe care îl reprezintă și de sensul pe care în dezvoltă. Verbele tranzitive reclamă obligatoriu un subiect și un obiect direct, iar facultativ, diverse complemente necircumstanțiale sau circumstanțiale. Verbele intranzitive se construiesc în mod obligatoriu cu un subiect, celelalte componente sintactice fiind, în funcție de sens, obligatorii sau facultative.

\section{Referințe bibliografice:}

1. BĂRBUȚĂ, Ion.Semantica și sintagmatica verbului. În: Revistă de lingvistică şi știință literară. 1996, nr. 3, p. 57-65.

2. CENAC, Oana Magdalena. Despre valorile verbului a face. În: Communication and Argumentation in the Public Sphere. (2007) Year I, Issue 2. ISSN 1843 - 7893 pp. 318-322; sau 
Oana Magdalena CENAC Despre valorile verbului a face Universitatea Dunărea de Jos, Galaţi, ROMÂNIA În: oanacenac@yahoo.com

3. CONSTANTINOVICI, Elena. Subcategorizarea semantică a verbelor de acțiune fizică. În: Materialele simpoziuonului internațional „Studii și cercetări economice - exigențe pentru Republica Moldova. IREI 2001", Chișinău, 2001.

4. CONSTANTINOVICI, Elena. Semantica și morfosintaxa verbului în limba română, Chișinău, CEP USM, 2007.

5. EVSEEV, Ivan. Semantica verbului. Categoriile de acțiune, devenire și stare. Timişoara, 1974.

6. GALR = Gramatica limbii române, 1, Cuvântul. Editura Academiei Române, 2005, p. 326-330.

7. PANĂ-DINDELEGAN, Gabriela. Sintaxa transformațională a grupului verbal în limba română, București, 1974.

8. VULPE, Ana. Verbele creării în limba română, Chișinău, CEP USM, 2002.

9. ZGÂRCIBABĂ, Elena. Consideraţii la sintaxa verbului a (se) face. În: Studia Universitatis Moldaviae. 2015, nr. 10(90), Seria „Științe umanistice”, p. 8-11.

Notă: Articolul a fost realizat în cadrul proiectului de cercetare 20.80009.1606.01 Valorificarea științifică a patrimoniului lingvistic național în contextul integrării europene, Institutul de Filologie Română „B.P.-Hasdeu” al MEC. 